\title{
The Constitution of Translation Competence and Its Implications on Translator Education
}

\author{
Yanqun Zou \\ C \& E Signs Research Center \\ Beijing International Studies University \\ Beijing, China \\ e-mail: belindazou@126.com
}

\begin{abstract}
How to enhance students' translation competence is the essential issue in translator education, while scholars have not reached an agreement on the components of translation competence. Reviewing the development of translation competence models in the past four decades, this study tries to clarify the constitution of $\mathrm{TC}$ in the ever changing world, and reveals the strategic competence the central competence that dominates, harmonizes, and optimizes other sub-competences. In the light of the previous researches, the study explores the implications of the central subcompetence in translator education to enhance TC effectively, to improve translation quality and efficiency, to cultivate conscious, autonomous, self-directed, competent translators and lifelong learners.
\end{abstract}

Keywords-translation competence; metacognition; implications; translator education

\section{INTRODUCTION}

The essential issue of translator education is to develop, cultivate and enhance trainees' translation competence (TC). With the globalization of economy, the great development in information technology, and multiplying demands in the applied translation, the ever changing world requires more qualified and competent professional translators to satisfy the needs of translation in the current context, consequently, translator and interpreter education becomes an urgent task, and the constitution of TC and its core competence become a crucial issue. However, scholars have not reached an agreement on it yet. Reviewing the development of TC models, this study discusses the components of TC in the current context and explores its implications in translator education.

The analysis on TC in the traditional Western and Chinese history of translation was less than comprehensive or systematic, while the subjective and objective requirements of translators were involved, which were predominantly about the linguistic and cultural competences based on translators' personal experiences in literature or religious translation. This study focuses on the TC models in the contemporary period when the translation materials and demands are changing dramatically. Presas states that translation is strongly influenced by three factors: directionality, modality and the specific language combination [1]. This study maintains that the TC in different circumstances share the nature, while certain factors, like directionality, modality, language combinations or specialization may have an impact on the route and rate of learning[2].

This article is one of the results of the project " $\mathrm{C}-\mathrm{E}$ Translation Teaching in Adult Education in Perspective of Translation Competence" funded by Beijing International Studies University, and the project "E-C Translation Teaching in Adult Education in Perspective of Translation Competence(CR1502)" approved by Beijing Adult Education Association.

Literature shows that long-term university-level training is a relatively recent phenomenon, mostly dating from the second half of the twentieth century and rising sharply in the late 1980s and early 1990s[3]. The development of TC models in the past four decades undergo four periods: the initial period-1970s, the early scholars do not differentiate TC from bilingualism, and claims TC as an innate skill, while later scholars argue $\mathrm{TC}$ is the result of nature and nurture. The discussions on TC in this period mainly confine to linguisitc competence, which is thought to be the core in TC. The main contributions include Harris \& Sherwood $(1973,1978)$, Toury (1974), Wilss (1976) in this period. The second period is the developmental period-1980s: scholars begin to see competences besides linguistic competence-world knowledge or disciplinary competence, instrumental competences, socialization of norms Toury (Nida1981, Robert1984, Toury 1986). 1990s is the enriching period with the adoption of functional theory on translation, and the vision becomes broader with the recognition of the contextual, communicative, functional, dynamic features of translation (Nord1991, Bell1991, Kiraly 1995, Hatim \& Mason1997, Shreve1997, Löscher1997, Vienne 1998). Borrowing ideas from the second language aquisition and intercultural communication, the TC models are being enriched in 1990s: instrumental competence, professional knowlege on translation, assessment \& monitoring competence, macro-strategy, disposition, and the interaction of subcompetences have been recognized (Nord1992, Gile1992, Hönig 1995, Cao1996, Hatim \& Mason1997, Presas1997, Vienne1998, Campbell1998, Hurtado 1999). The publication of Developing Translation Competence 
(2000) marks the studies on TC come into the blooming period: the relevant researches employ various empirical research methods, and borrow ideas from psychology, sociology and intercultural studies to analyze the issue from different respects - constitution, pedagogy, measurement, and test in terms of interdisciplinary perspective. Scholars take a holistic approach towards TC to satisfy the demands of the ever changing and updating society, and develop more comprehensive, systematic, and well-defined TC models. (Neubet 2000, Schaffner2000, Fraser 2000, Beeby 2000, Fox2000, Sim 2000, Yang 2002, Jiang \& Quan2002, Liu 2003, Colina 2003, Pym 2003, Davies 2004, Kelly 2005, Miao 2006, Wang \& Wang 2008, Göpferich 2009, Wen \& Li 2010, Pacte 2003, 2011, Tao 2012, Ma 2013, Wang 2013). PACTE group $(2000,2003,2005,2009,2011,2014)$ contributes a series of prominent results of their researches in over ten years, proposing a systematic, strategy-oriented model covering linguisitc, extra-linguistic, strategic, instrumental, professional knowledge on translation subcompetences and psycho-physiological factor. With the development of the past four decades, most scholars "agree that translation competence consists of several different subcompetences which integrate declarative and procedural knowledge. However, they seem to differ in what should be emphasized first in the training of translators" [4].

\section{REVIEWING TC MOdels IN PERSPECTIVE OF CENTRAL COMPETENCE}

In light of the previous researches (Pym 2003, Wang 2013), the study classifies the TC models in perspective of the possibility or necessity to develop TC into two general categories: TC is an innate competence-- TC could not or need not to be cultivated or taught; TC could be cultivated and learned, which proves the necessity and significance of translator education. The latter could be categorized into language-oriented, transfer-oriented, and communicationoriented TC models in perspective of the central competence "Fig. 1".

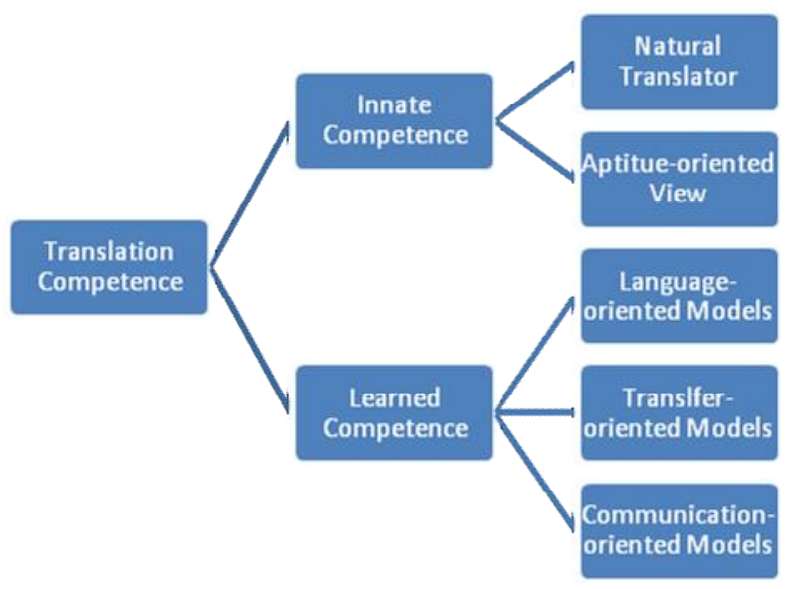

Fig. 1. Classification of TC Models

\section{A. Translation Competence as an Innate Competence}

Harris \& Sherwood consider TC an innate skill, "all bilinguals can translate" without formal training [5] and it is a universal, innate verbal skill, and natural translation develops within "the limits of mastery of the two languages"[6]. Harris \& Sherwood's focus on the decisive importance of language competence and spontaneous development without training confines their research within the investigation of non-professionals' TC, which is differentiated from the current view of the expert translation competence that indicates conscious reflection on translation(what) and abilities to translate effectively and efficiently(how). As Shreve says, this form of translation competence emerges fully as a by-product of evolving bilingualism [7]. Harris \& Sherwood fail to distinguish translation competence from bilingual competence. Toury $(1986,1995)$ modifies the native translator view, and argues that $\mathrm{TC}$ requires both innate predisposition and nurture in translation education.

Nida (1981) claims that effective translators are born and not made. Nida (2001) once says, some of the best translators have no training whatsoever in linguistics. Brilliant translators are often surprised at the manner in which creative solutions seem to pop into their heads. Since translating is a skill which requires considerable practice, most people assume that it can be taught, and to some extent this is true. But it is also true that really exceptional translators are born, not made [8]. What Nida meant is that the best, brilliant translators require aptitude and gift; and at the same time, TC does not depend on aptitude completely, but could be taught to some extent. Yang (1998) holds the same view. Furthermore, Nida develops his understanding about translation competence, which requires "bilingualism, biculturalism, adequate knowledge of the content of a text", and "competence in writing" [8]. Therefore, Nida maintains that $\mathrm{TC}$ requires both nature and nurture, while the really brilliant, outstanding translators demand certain aptitude. However, outstanding translators are limited, while the intercultural communication demands are increasing with multiplying texts to be translated, which requests more qualified and competent translators to fulfill the communicative function. Consequently, to develop qualified and competent translators is the call of the age, the demand of the market, and the meaning of translation education.

What Harris \& Sherwood and Nida focus on are the two extremes: the nonprofessionals at the beginning of translation and the best, brilliant, outstanding translators, which are not the focus of general translation education nor the research. What translation education prioritizes is to develop trainees' TC by assisting them develop conscious reflection on translation, get equipped with necessary declarative, procedural and conditional knowledge to tackle with problems encountered in translation, and help them become qualified and competent translators to fulfill the communicative functions effectively in the current context.

\section{B. TC as a Competence That Could Be Learned \\ 1) Language-oriented translation competence models}


Language-oriented TC models run through the four periods. Harris (1973) considers translating as an innate skill of bilinguals. Delise (1980) believes that TC includes language competence, encyclopedic competence, and competence of comprehension and expression. Campbell (1991) identifies two components of translation competence: disposition and proficiency. Presas (1997) puts forward the language-based core competencies, including ST reception, production of a draft TT, and production of a final TT, and some "peripheral competencies" that cover instrumental competence, area knowledge, uses of briefs [9]. Yang (2002) points out that linguistic competence is the core of TC explicitly, besides encyclopedic knowledge, professional knowledge on translation, and comprehensive competence. Wang (2013) maintains the linguistic-textual-pragmatic competence the core subcompetence.

Linguistic competence is the basis and prerequisite of TC, nevertheless, it is not the translation-specific competence. It is admitted that bilingual competence were the most important part in TC, and played a decisive role in translation quality and efficiency before information technology has been developed--what translators could do was to draw relevant information from the brain with very little help of instruments. Given the development of relevant disciplines--psychology, sociology, linguistics, information technology, translation, and the content of translation in 1970 s, TC is confined in linguistics, however, it is a good starting point, offering inspirations for further researches. But when it comes to 1990 s and $21^{\text {st }}$ century, the languageoriented TC models overlook the dramatic changes in the translation materials, demands, market, technologies and context, overlook the essence of TC in the current context, and remain a static perspective on translation. With the dramatic development of information technology, the decisive factors to improve translation quality and efficiency involve strategic, instrumental and knowledge about translation subcompetences to satisfy the communicative and functional demands of translation, with linguistic \& cultural competences as the prerequisite.

\section{2) Transfer-oriented translation competence models}

The transfer-oriented models includes two views: static models emphasizing the static transfer of languages and dynamic models reflecting the communicative and dynamic features of translation.

Wilss maintains that $\mathrm{TC}$ requires linguistic, textual knowledge of the source and target language, and the supercompetence, which "implies the ability to synchronize these two monolingual and intertextual transfer" [10]. Robert's (1984) translational competence model includes translation competence, which is defined as "the ability to comprehend the meaning of the source text and express it in the target text without undue changes in form and avoiding interference", besides linguistic, disciplinary and instrumental competences [11]. Neubert's (2000) TC model includes transfer competence, which is "the distinguishing domain of a translator", and "dominates over all the other competencies, i.e. transfer skills integrate language, text, subject and culture knowledge with the sole aim of satisfying transfer needs." Although the dynamic feature has been recognized--“"They favour the dynamics of doing as against the statics of 'just' knowing", it is not reflected in Neubert's model [12]. Jiang \& Quan (2002) believes that TC includes transfer competence, besides linguistic competence, cultural competence, aesthetic competence. The communicative, functional and dynamic feature of translation is not indicated [13].

Wilss's supercompetence, Roberts' translation competence, and Neubert and Jiang\& Quan's transfer competence, are a kind of comprehensive macrocompetence, which demands the involvement of the other subcompetences to produce the target text and fulfill the translation task, as what Neubert says. With different terms, this kind of general competence is a circular concept to the general concept of translation competence.

Being more conscious of the significance of the functional theory in translation in 1990s, more scholars realize the contextual, communicative and functional features of translation, and take a dynamic perspective. Nord's (1991) TC model includes competence of text reception and analysis, research competence, transfer competence, competence of text production, competence of translation quality assessment, and linguistic and cultural competence both on the source and the target side, which is the main prerequisite of translation activity, and the communicative function is the decisive criterion of textuality [14]. What features Nord's model is the adoption of functional perspective towards translation, which allows us to perceive the contextual, communicative and dynamic nature of translation, as a consequence, translation is understood from a broader, and more profound perspective in 1990s, which is of decisive importance in translation. Additionally, the competence of translation quality assessment belongs to metacognition.

Bell's (1991) translator competence covers "the inference mechanism which permits: the decoding and encoding of texts, which is a kind of transfer competence, besides bilingual, domain, and communicative competence [15]. Based on Bachman's model of communicative language ability, Hatim\&Mason propose the model of translator competence: source text processing skills, target text processing skills, and transfer skills, in which they involve the effectiveness, efficiency, relevance to audience, design, task, which demonstrates translator as communicator [16]. Schäffner defines TC as "a complex notion which involves an awareness of and conscious reflection on all the relevant factors for the production of a target text (TT) that appropriately fulfils its specified function for its target addressees". Besides linguistic, cultural, textual, and domain/subject competence, her TC model includes: transfer competence - ability to produce TTs that satisfy the demands of the translation task, and (re)search competence - a general strategy competence whose aim is the ability to resolve problems specific to the cross-cultural transfer of texts [17]. Realizing the dynamic 
feature of translation, Schäffner considers transfer competence the translation specific competence, which integrates all the other sub-competences. Besides contrastive linguistic contrastive, extra-linguistic, and discourse competence, Beeby's TC model includes transfer competence--awareness of the translation process, awareness of multiple contexts, awareness of the interdependence between micro and macro structures in text and translation, in which the contextuality is stressed. Moreover, Beeby stresses the importance of instrumental competence (Documentation skills) in translation [18]. PACTE's (2000) model includes transfer competence as the core, besides bilingual communicative competence, extralinguistic competence, knowledge about translation competence, psycho-physiological competence, and strategic competence [19]. Davies develops his TC model with his students in a class activity, which includes linguistic, encyclopedic knowledge, and transference skills-"optimize(s) the relation established between linguistic competence and encyclopedic knowledge, and to transfer the source text for a target audience appropriately are at the basis of translation competence" [20], which highlights the function of the translation task and the integrating feature of transference skills. Furthermore, he points out decisionmaking (strategic competence), resourcing skills (tools competence) and mental characteristics are the specific and central competences of translation, which reflects his comprehensive understanding of the nature of TC.

The static transfer-oriented TC models are found mostly in 1980s and 1990s; with the recognition of functional theory in translation, the dynamic transferoriented TC models are found in 1990s and the early 2010s. Those who hold the static and dynamic transfer-oriented views fail to realize that transfer competence requires the participation of all the other sub-competences to fulfill the communicative function, thus transfer competence is a circular concept to translation competence.

\section{3) Communication-oriented translation competence} models

The communication-oriented TC models include two views: the non-strategic perspective, and the strategic perspective with strategic competence as the core.

Gile's TC model contains: the procedural knowledge (techniques and skills)--knowing how to translate, besides linguistic and subject competence [21]. What characterizes Gile's model is the emphasis on professional translation competence, which is communicative-oriented, peopleoriented, instead of a language-centered activity, thus, translators should assess the communicative effect of their target-language text or speech [22], which highlights the situational, communicative feature of translation and the importance of metacognition.

Kiraly adopts the term--translator competence, rather than translation competence for the following two reasons: emphasis is placed on the complex nature of the professional translator's task and the nonlinguistic skills that are required [23]. From the above mentioned TC models, we could conclude that the complexity of translation and the nonlinguistic competences have been recognized. As a consequence, the differentiation of translation competence and translator competence seem less necessary. However, Kiraly lays emphasis on the situational and communicative feature of translation, and includes the monitoring ability, concerning cognitive and meta-cognitive competence.

Nord(1996) lists the knowledge, skills and abilities that are necessary to translate: Abilities include: analysis, making decisions, creativity, evaluation(translation quality assessment); knowledge include: source \& target language and culture, translation theory and methods; skills include analyzing translation briefs, text analysis in the SL, planning strategies, text production in the TL, recherché[24]. "Planning strategies", "evaluation", and "making decisions" reveal Nord's awareness of the participation of metacognitive competence in translation. Campbell's (1998) modified model covers monitoring competence, which is part of metacognition, besides linguistic competence and disposition [25].

Pym (2003) proposes the following two abilities the core of TC: "the ability to generate a series of more than one viable TT for a pertinent ST" and "the ability to select only one viable TT from this series, quickly and with justified confidence" [26]. The former is the embodiment of translation competence, rather than the translation competence itself, while the latter is necessary rather than translation-specific competence. However, Pym covers linguistic competence (grammar, rhetoric), extra-linguistic competence (world knowledge), instrumental competence (terminology, computer skills, Internet savvy), professional translation competence (teamwork cooperation, strategies for getting paid correctly) in the further elaboration, and he concludes translation as "a problem-solving process", which demonstrates the profound understanding of TC. Nevertheless, these are not reflected in the model. Kelly (2005) and Ma (2013) take a functionalist approach to translation, considering communicative competence plays an importance role in TC.

Since the adoption of functional theory in translation, scholars develop from language-oriented and transferoriented perspectives to non-strategic communicationoriented perspective, which is discussed profoundly in 1990s and 2010s. Some researches cover some factors of metacognition, but the strategy or metacognition is not proposed as the core explicitly then.

Hönig (1988) claims that translation is a principled, strategic process, in which the macro-strategy is emphasized [27]. Based on Bachman's model for communicative language use, Cao's (1996) translation proficiency includes: translational language competence, translational knowledge structures, and translational strategic competence, which is the linkage that relates translational language competence to knowledge structures and to the features of the context in translation, so that the interlingual and cross-cultural 
communication take place [28]. Cao not only proposes strategic competence explicitly, but also points out the integrating function of strategic competence to other subcompetences. Approving the necessity of language skills, Vienne emphasizes two abilities as the core of TC: "The ability to analyze a variety of translation situations", and "to produce a specification, in broad outline, of the strategy to be pursued in order to achieve the desired outcome" [29]. Fox's model of TC covers learning-how to learn and problem-solving goals, which belong to metacognition, besides communicative competence, socio-cultural competence and language and cultural awareness [30].

The PACTE group uses empirical-experimental research methods, including PROXY software, TAPs, questionnaire, experiment, and observation to investigate the constitution of translation competence and how it is acquired. TC is defined to be the underlying knowledge system needed to translate and has four distinctive characteristics: (1) it is expert knowledge and not possessed by all bilinguals; (2) it is basically procedural knowledge (and not declarative); (3) it is made up of various interrelated sub-competencies;(4) the strategic component is very important, as it is in all procedural knowledge. The modified model (2003) is made up of 5 sub-competencies and psychophysiological components [31] "Fig. 2".

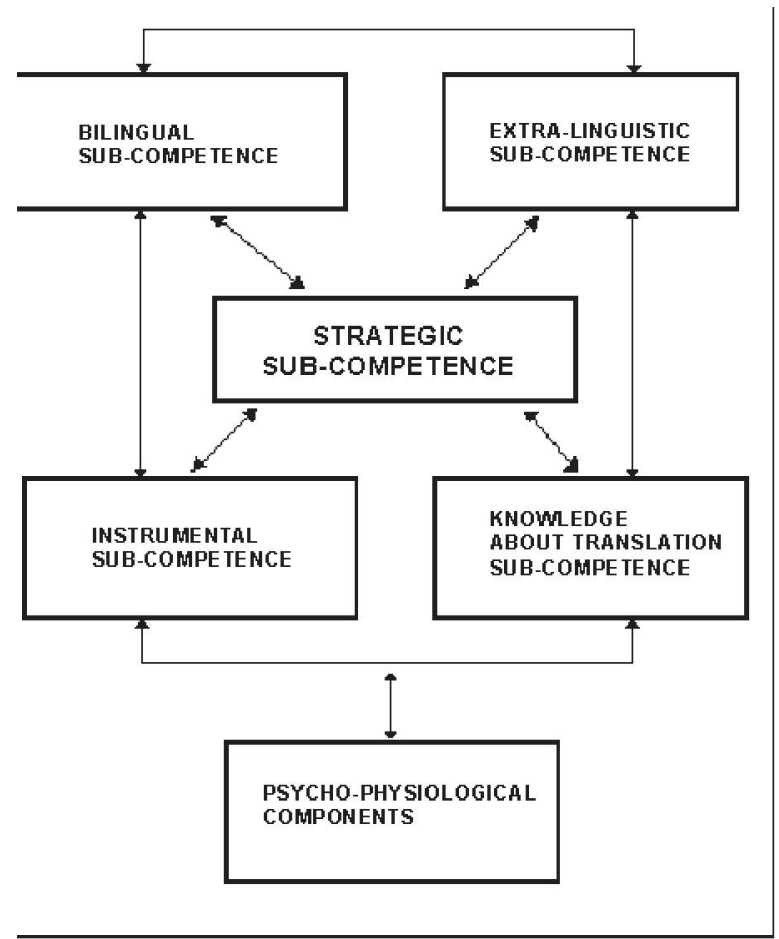

Fig. 2. PACET Model (2003)

a) Bilingual sub-competence.(pragmatic, sociolinguistic, textual, grammatical and lexical knowledge).

b) Extra-linguistic sub-competence(general world knowledge, domain-specific knowledge, bicultural and encyclopedic knowledge). c) Knowledge about translation(how translation functions and knowledge about professional translation practice)

d) Instrumental sub-competence(the use of documentation resources and information and communication technologies applied to translation).

e) Strategic sub-competence -to guarantee the efficiency of the translation process and solve problems encountered. (plan and carry out the translation project, evaluate the process and the partial results obtained in relation to the final purpose; activate the different subcompetences and compensate for any shortcomings; identify translation problems and apply procedures to solve them).

f) Psycho-physiological components[32]. Given that any bilingual has knowledge of two languages and may have extralinguistic knowledge, PACTE consider that the sub-competencies specific to TC are the strategic, the instrumental and knowledge about translation. This model is a comprehensive, systematic TC model that reflects the nature of translation. However, the extra-linguistic competence and knowledge about translation are also supposed to be procedural knowledge, which involves the flexible and dynamic evaluation in different circumstances; and conscious reflection on how translation function is supposed be included in knowledge about translation.

Inspired by the PACTE group's model, Göpferich (2009), based on longitudinal studies, claims that strategic, translation routine activation and tools/research competence are the translation-specific competencies with communicative competence, domain competence and psychomotor competence included in the model[33]. Göpferich's model is a comprehensive one, and points out the interaction between sub-competences, while there are certain confusions. Firstly, the professional translation competence is removed from the center and put at the bottom as the basis - translation norms, translation brief (assignment), professional ethos. I believe that the translation-specific sub-competences are those play decisive roles in translation quality and efficiency in the present circumstance, those that differentiate the professional translators from bilingual speakers. Consequently, the central translation competence would not be complete without professional translation competence. Secondly, translation routine activation competence is once explains as "knowledge about how translation function, types of translation units, processes required, methods and procedures used(strategies and techniques), and types of problems", which could be categorized into professional knowledge about translation, while in the model she explains as "knowledge and abilities to recall and apply certain -mostly language-pair-specific-transfer operations which frequently lead to acceptable target-language equivalence", which displays the linguistic-oriented perspective overlooking the functional, dynamic and situational features of translation; furthermore, translation routine activation competence is explained as abilities to 
realize "transfer operations(or shifts)", which requires the involvement of other sub-competences, and is a circular term of TC. Thirdly, the self-concept and motivation could be included in psycho-physical disposition. Wen \& Li (2010) include strategic competence in their TC model without pointing out its dominating role.

Scholars are becoming more and more conscious of the dominating and integrating role of strategic competence in $\mathrm{TC}$, of the translation-specific competences--strategic, instrumental, and knowledge about translation competences that differentiate professionals from amateurs, with linguistic and extra- linguistic competences as the prerequisite in the ever changing and updating society. The macro-strategy, the ability to learn and solve problems, or the strategic competence to solve problems encountered in translation belong to metacognition. PACTE's model is the most comprehensive, systematic, and well-defined TC model that reflects the communicative, functional and dynamic features of translation, and reveals the translationspecific competences. The instrumental competence and knowledge about translation have been covered in the present translator education, therefore, this study focuses on strategic competence--metacognition in translator education. Metacognition is defined as knowledge and regulation of cognition: metacognitive knowledge includes the cognition of the subject (knowledge, ability, resources, cognitive, affective and physiological state), others, cognitive universals, the task, as well as metacognitive awareness; metacognitive regulation involves planning to maximize the resources in certain context prior to performing a task; monitoring, regulating to optimize the performance during the task; and evaluating and reflecting cognitive process after the performance [34].

\section{METACOGNITION IN TRANSLATION}

The significance of strategic competence has been recognized, however, the value and function of metacognition remains to be elaborated in TC and translator education. Firstly, the enhancement of metacognition is the call of the age. With the constant development of disciplines and technology, especially information technology, translators are facing a world with constantly updating information, with unpredictable problems to be solved in translation tasks, which require metacognition to optimize the knowledge, abilities, resources mastered, to monitor the process of problem solving, and reflect on what has been performed, in order to complete tasks efficiently, effectively and keep on the track of progress. Translator education is becoming more challenging, because the programs "have to try to cater for the huge diversity in the current market, while at the same time foreseeing likely future developments students should be prepared for"[35]. And metacognition is the key.

Secondly, metacognition is the call of the essential features of TC for the time being. With a comprehensive survey of the TC models from 1970s, we have seen the understanding of TC developing from linguistic-oriented, transfer-oriented ones to strategy-oriented models, from models in static linguistic perspective to models in dynamic, functional and communicative perspective. Drawing lessons and inspirations from the TC models of the past several decades, and we are supposed to take a historical perspective. When information technology was less developed in 1970s and 1980s, the instrumental and strategic competences were not as prominent; when translation was largely confined within religion and literature with less need in applied translation, the communicative, functional and dynamic features were not as significant in 1970 s and 1980s, while the linguistic competence did play an importance role in $\mathrm{TC}$ for that period of time. However, with the great development in information technology and multiplying demands in applied translation, the constitution of translation competence of qualified and competent translators is being clarified highlighting the contextual, communicative, functional and dynamic features of translation, which demands cognition and metacognition to perform the complex, unfamiliar, and non-routine tasks with dynamic requirements. Consequently, metacognition plays the dominating role in translation competence, which sets priorities and defines hierarchies between the individual sub-competences [36].

Being the central, decisive component in $\mathrm{TC}$ for the time being, metacognition dominates, coordinates, and facilitates the development of other sub-competences. Metacognition maximizes and optimizes the knowledge, abilities, resources at disposition with certain language competence, and supports the improvement of translation quality and efficiency; it is the prerequisite to satisfy the demands of the dynamic, contextual, communicative, functional translation tasks; it is what equips and ensures translators to become self-directed, autonomous, competent lifelong learners, and keep making progress in translation; it is what qualified translators need to adjust to the ever changing and developing society, information and technology; it is the core to become capable and efficient translators in the current context. Therefore, metacogntion is to be stressed and highlighted in TC and translator education. As Baer and Koby write, "We may hope to better prepare students for the workplace by offering them appropriate tools, but if our teaching methodology is of the traditional kind-performance magistrate described by Jean-René Ladmiral (1977) in which the master passes on his/her knowledge to passive apprentice - we may fail to procduce translators who are capable of the flexibility teamwork and problem-solving that are essential for success in the contemporary language industry [37]. And the instrumental competence and knowledge about translation competence are of significance in TC, which will be discussed in the following papers.

\section{Limitations OF PRESENT STUdiES AND SUGGESTIONS}

TC studies have developed for over four decades with great progress and achievement, while there is still room to be improved. Firstly, the subjects in TC studies are 
comparatively limited, mostly limited within 10-60 subjects, and it needs larger samples to prove the results. Secondly, the validity of the research methods and measurements need to be analyzed thoroughly, and the noises and disturbing factors need to be taken into consideration. So that the scholars could choose the appropriate research methods-PROXY software, TAPs, electronic translog software, eye tracking, key-logging and other methods adopted by psychological researches, and the traditional methods, questionnaire, interview, experiment, observation etc. as well. Thirdly, only a few researches take the longitude study method due to the consumption of time and energy, while the development of TC demands large scale longitude study to explore the different roles of respective subcompetences in different stages, and the interaction of subcompetences. Fourthly, researchers may build professional and students' translation corpora to develop longitude and contrastive studies, to boost the TC studies in different perspectives with empirical data.

\section{IMPLICATIONS ON TRANSLATOR EDUCATION}

The current translator education mainly focuses on linguistic \& cultural competences and professional knowledge about translation with instrumental competence as an additional one, while the strategic competencemetacognition remains to be elaborated and developed in curriculum design, teaching philosophy, teaching methods, feedback and tests. Instructional strategies intended to develop students' metacognitive abilities must be infused into our teaching methods, staff development, and supervisory processes [38]. In terms of curriculum design, metacognition is supposed to be included and integrated in each stage in translator education, and activate students' metacognitive awareness and enhance their metacognitive competence. In teaching principle, translation education needs to move from product-oriented education to processoriented education, and lay emphasis on the development of TC-procedural and conditional knowledge, rather than the mastery of static, declarative knowledge. In terms of teaching methods, teachers are to cultivate the classroom culture to allow and encourage students to do self-guided questioning, strategies selection, evaluating, reflection to ensure the task is performed effectively. As Livingston (1996) says, simply providing knowledge without experience or vice versa does not seem to be sufficient for the development of metacognitive control, metacognition is supposed to be integrated in concrete translation activities [39]. The adoption of task-based and project-based teaching methods would offer students opportunities to encounter the possible difficulties and challenges; the employment of diverse classroom activities--jumpstart journal, the muddiest point, think-pair-share, letters to future students, teacher modelling, the introduction of Cornell note taking system, reflective journal, group study, peer review would activate students' metacognitive awareness and enhance their strategic competence, particularly the abilities to evaluate, optimize, reflect, regulate and monitor, which should be integrated to each and every session in translation-before, in, and after translation. Additionally, teachers need to give comprehensive and systematic feedback to students in time in process-oriented perspective. In tests, teachers are to move from diagnostic evaluation to formative evaluation, and integrate monitoring and reflection into credited course work at the beginning to facilitate developing students' metacognition. And it remains to be developed how to evaluate students' metacogniton in examinations. At the same time, teachers' metacognition needs to be enhanced.

\section{CONCLUSION}

Reviewing the development of TC models in the past four decades, this study discusses the language-oriented, transfer-oriented, and communication-oriented TC models, clarifies the central competence and the translation-specific competences in the current context, highlighting the dominating role of strategic competence, and explores its implications to translator education. The future researches are to lay more emphasis on the different roles of the subcompetences in different stages, and the interaction of the subcompetences, as well as the building of professional and students' corpora to develop TC studies in different perspectives, to enhance TC effectively, to improve translation quality and efficiency, to cultivate conscious, autonomous, self-directed, competent translators and lifelong learners.

\section{REFERENCES}

[1] Presas, M. "Bilingual competence and translation competence". In Christina Schäffner \& Beverly Adab (eds.). Developing Translation Competence. Amsterdam: John Benjamins, 2000, pp.23-25.

[2] PACTE. "Building a translation competence model". In Alves, Fabio (ed.) Triangulating Translation: Perspectives in Process Oriented Research, Amsterdam: John Benjamin, 2003, pp.84. Pym, A. Translator training. 2009.Retrieved Feb. 10 $0^{\text {th }}, 2015$ from

[3] http://www.doc88.com/p-708929278628.html.

[4] Alves, F. "Bridging the gap between declarative and procedural knowledge in the training of translators:Meta-reflection under scrutiny. Meta: Translators'Journal.2005, 50(4). Retrieved from http://www.erudit.org/revue/meta/2005/v50/n4/019861ar.pdf.

[5] Harris, B. The importance of natural translation. Working Papers on Bilingualism, 1997, 12, pp. 96-114.

[6] Harris, B. \& Sherwood, B. "Translating as an innate skill". In D. Gerver \& H. W. Sinaiko(eds.), Language, Interpretation and Communication. New York: Plenum, 1978, pp.155.

[7] Shreve, G. Cognition and the evaluation of translation competence. In Joseph H. Danks et al.(eds.) Cognitive Process in Translation and Interpreting. Thousand Oaks: Sage Publications, 1997, pp.121.

[8] Nida, E. A. Language and Culture: Context in Translating. Shanghai: Shanghai Foreign Language Education Press, 2001, pp.100.

[9] Pym, A. "Redefining translation competence in an electronic age". Meta. 2003, 48(4), pp. 481-497.

[10] Wilss, W. "Perspectives and limitations of a didactic framework for the teaching of translation". In Richard W. Brislin(eds.) Translation: Application and Research. New York: Gardner,1976, pp.120.

[11] Vienne, J. "Teaching what they didn't learn as language students". In Kirsten Malmkjær(eds.) Translation and Language Teaching : Language Teaching and Translation. Manchester: St. Jerome,1998, pp. 111 .

[12] Neubert, A. "Competence in language, and in translation". In C. Schäffner \& B. Adab(eds.) Developing Translation Competence. Amsterdam: John Benjamins, 2000. 
[13] Jiang, Q. \& Quan, X. "On the relation between translation competence and translation behavior". China Translator Journal, 2002(6), pp.11-15.

[14] Nord,C. "Text analysis in translator training". In C. Dollerup \& A. Loddegaard(eds.) Teaching Translation and Interpreting. Amsterdam: Benjamins, 1992, pp.42-47.

[15] Bell, R. Translation and Translating: Theory and Practice. London: Longman, 1991.

[16] Hatim, B. \&Mason I. The Translator as Communicator. London: Routledge, 1997, pp.205.

[17] Schäffner, C. "Running before walking? Describing a translation program”. In Christina Schäffner \& Beverly Adab(eds.). Developing Translation Competence. Amsterdam: John Benjamins, 2000, pp.146.

[18] Beeby, A. "Evaluating the development of translation competence". In Christina Schäffner \& Beverly Adab(eds.), Developing Translation Competence. Amsterdam: John Benjamins, 2000, pp.186-187.

[19] PACTE. "Acquiring translation competence: Hypotheses and methodological problems in a research project". In Beeby et al. (eds.) Investigating Translation, Amsterdam: John Benjamins, 2000.

[20] Davies,G. Multiple Voices in the Translation Classroom. Amsterdam: John Benjamins, 2004, pp.130-132.

[21] Gile, D. Basic Concepts and Models for Interpreter and Translator Training. Amsterdam: John Benjamins, 1995, pp. 8-10.

[22] Gile, D. "Basic theoretical components in interpreter and translator training”. In Cay Dollerrup \& Anne Loddegaard(eds.) Teaching Translation and Interpreting: Training, Talent and Experience. Amsterdam: John Benjamins, 1992, pp.187.

[23] Kiraly, D. Pathways to Translation: Pedagogy and Process. Kent: The Kent State University Press, 1995, pp.16-17.

[24] Nord, C. "El error en la traduccion: categorias y evaluacion". In A. Hurtado(eds.) La ensenanza de la traduccion. Castello: Universitat Jaume, 1996.

[25] Campbell, S. Translation into the Second Language. London: Longman, 1998.

[26] Pym, A. "Redefining translation competence in an electronic age". Meta, 2003, 48(4), pp. 481-497.

[27] Hönig, H. Wissen Übersetzer eigentlich, was sie tun? [Do translators really know what they do?] Lebende Sprachen, 1998, 33(1), pp.10-14.

[28] Cao. D. "On translation language competence". Babel, 1996, 42(4),pp.231-238.

[29] Vienne, J. "Teaching what they didn't learn as language students". In Kirsten Malmkjær(eds.) Translation and Language Teaching Language Teaching and Translation. Manchester: St. Jerome, 1998, pp.91-93.

[30] Fox, O. "The use of translation diaries in a process-oriented translation teaching methodology". In Christina Schäffner \& Beverly Adab(eds.), Developing Translation Competence. Amsterdam: John Benjamins, 2000, pp.117.

[31] PACTE. "Building a translation competence model". In Alves, Fabio (ed.) Triangulating Translation: Perspectives in process oriented research. Amsterdam: John Benjamin, 2003.

[32] PACTE. "Results of the validation of the PACTE translation competence model: Translation problems and translation competence". In Alvstad et al. (eds.) Methods and Strategies of Process Research: Integrative Approaches in Translation Studies. Amsterdam: John Benjamins, 2011, pp. 4-5.

[33] Göpferich, S. \& Riitta J. "Process research into the development of translation competence: Where are we, and where do we need to go? Across Languages and Cultures, 2009, 10(2), pp. 169-191.

[34] Zou, Y. "The concept and instruction of metacognition in translation competence development". International Forum of Teaching and Studies. 2015, in print.

[35] Kelly, D. A Handbook for Translator Trainers. Manchester: St. Jerome, 2005, pp.27.

[36] Göpferich, S. \& Riitta J. "Process research into the development of translation competence: Where are we, and where do we need to go?" Across Languages and Cultures, 2009, 10(2), pp.169-191.
[37] Baer, B.J.\& Koby, G. S. "Introduction: Translation pedagogy: The other theory". In Baer, B.J.\& Koby, G. S.(eds.), Beyond the Ivory Tower. Amsterdam: John Benjamins, 2003, pp.vii-viii.

[38] Coasta, A. "Mediating the metacognitive". Educational Leadership, 1987, 42(2), pp.57-63.

[39] Livingston, J. "Metacognition: An overview". Retrieved Feb. 10 ${ }^{\text {th }}$, 2015 from http://gse.buffalo.edu/fas/shuell/cep564/metacog.htm,1996. 